\title{
Proceeding
}

Supplementary Issue: Winter Conferences of Sports Science. Costa Blanca Sports Science Events, 24 April 2020. Alicante, Spain.

\section{Performance anxiety: How to play reliable and rational tennis by reducing mental pressure}

\author{
GIOVANNI ESPOSITO , ROSARIO CERUSO, FRANCESCA D'ELIA, TIZIANA D'ISANTO
}

University of Salerno, Italy

\begin{abstract}
Almost all tennis players, from beginners to professionals, would be able to perform better, and therefore be more performing, if only they were able to lower the level of mental pressure during a game. When it increases dramatically, it is the cause of technical, tactical errors and unorthodox attitudes, as well as significantly reducing confidence in one's own means. The purpose of this study is to identify the most appropriate tactical and technical behaviours to adopt in the sport in question to play a more reliable tennis in the various game situations. The method is empirical research for the analysis of technical and tactical. The method is empirical research for the analysis of technical and tactical foundations, with a subsequent comparative method between grids of indicators, descriptors and weights that classifies the behaviours to be adopted. The data are useful to provide a practical guide to follow in order to approach this sport correctly, especially for children, reducing the responsibilities incurred by them and eliminating the expectations of parents and trainers about them. The results are useful for any reflections and focus on the reproducibility of the topic investigated to other sports activities through an educational and training action.

Keywords: Mental training; Performance anxiety; Technical and tactical fundamentals.

Cite this article as:

Esposito, G., Ceruso, R., D'Elia, F., \& D'Isanto, T. (2020). Performance anxiety: How to play reliable and rational tennis by reducing mental pressure. Journal of Human Sport and Exercise, 15(2proc), S213S221. doi:https://doi.org/10.14198/jhse.2020.15.Proc2.12
\end{abstract}

Corresponding author. University of Salerno, Italy. https://orcid.org/0000-0002-3659-8943

E-mail: g.esposito198@studenti.unisa.it

Supplementary Issue: Winter Conferences of Sports Science. Costa Blanca Sports Science Events, 24 April 2020. Alicante, Spain.

JOURNAL OF HUMAN SPORT \& EXERCISE ISSN 1988-5202

(c) Faculty of Education. University of Alicante

doi:10.14198/jhse.2020.15.Proc2.12 


\section{INTRODUCTION}

Tennis, more than other sports, is a game of the mind, it is complicated and unpredictable. There are countless potential distractions, internal and external to a player, that hinder the achievement of maximum performance. More a player will be able to ignore or overcome them, more he will be concentrated. During a match it may happen that the player, suddenly, repeatedly fall into error or commit naivety that previously would never have occurred, the so-called "blackouts". Mental pressure is the main cause, especially among young people, of the many abandonments of this sport (Aryanto \& Larasati, 2020). There are several factors that the tennis player must consider in order to improve himself. First of all, he must be convinced that he is on the wrong track, and make sure he has the right motivation to change his playing style. Secondly, it is necessary to look for a good teacher who can give adequate suggestions and keep in mind that tennis must adapt to the player's psychophysical characteristics, and not vice versa (Altavilla, 2019). It is necessary to work hard during training sessions, but also to have a lot of fun. When any activity is practiced with pleasure, it is more likely to be continued over time and, certainly, learning will also benefit (D'Elia et al., 2019). From time to time, it will also be necessary to establish wider margins, both on the net and in relation to the lines that delimit the useful spaces, to train the fundamental skills (Altavilla et al., 2015). In this way, the players will have easier tasks to perform, which will continuously fuel their tennis' self-esteem. After the necessary training sessions with long exchanges with the teacher, they must therefore try to gradually transfer these new technical-tactical settings to the game. When the player will realize that he can perform these fundamentals with minimal mental effort then, then we can say that he have finally acquired the automatisms necessary to play tennis with their mind free from insecurities (Lauer et al., 2020). The player will have to convince himself that for improving, he will have to continuously try to play, without the fear of making mistakes. He must understand that defeat in a match will not diminish his value or his tennis career in the least, on the contrary, it will be the opportunity to acquire new experiences (Gaetano et al. 2015). From defeat it is necessary to start again with valid and new technical-tactical elements to work on (Pisano et al., 2019). Last tip, but not least, refers to the player's physical and athletic condition. Having a tennis match knowing that you are in good health certainly helps. It increases confidence, calms the mind and helps to lower mental pressure (Mamassis \& Doganis, 2004). Moreover, good physical preparation improves all the most important functions of our body and in the young in particular, together with proper nutrition, it is the essence of healthy growth. For the adult, however, it is a true prevention of the many problems that inevitably arise over the years. In many cases, good physical preparation can even replace medical-pharmacological therapies without undesirable effects (Raiola et al., 2018). Playing tennis more reliable and with less mental pressure is decidedly convenient, because it is more fun and profitable, it encourages to play more often and also guarantees to keep playing longer through the years. (Marsico et al., 2019). Starting a sport as a child and continuing it for the whole period of studies and, even up to a very old age, can also mean a lot for parents, who will have the awareness of having well invested their money and their sacrifices. After the generic concepts and the various suggestions that have the sole purpose of giving some useful information and clarifying the ideas on the goodness of this eventual turning point, we will analyse what to do practically to have a more reliable tennis with less mental pressure.

\section{Aim of the study}

The aim of this study is to identify in the game of tennis the significant elements of the fundamentals of the game and the related tactical technical behaviour to be adopted in the various game situations to lower the level of mental pressure. All this allows us to define an inventory of significant behaviours to be subjected to qualitative processing. The value of each of them will also be measured with respect to the other current behaviours of qualitative performance by establishing connections. 


\section{MATERIAL AND METHODS}

On the one hand, the method involves empirical research for the analysis of the fundamentals that characterize the sport in question. On the other hand, it provides a comparison between grids of indicators, descriptors and weights (i.e. the degree of connection between indicator and descriptor) that allows to classify the fundamental, the technique and the tactics. In the first phase, after identifying the theme, problem and aim, a bibliographic research enriched with the vision of a series of meetings between amateur tennis players was conducted. We have come to the definition of the technical fundamentals under investigation, with which we have tried to establish later, a connection with the technical and tactical aspects necessary to achieve the specific objective set. These measures are aimed at facilitating the execution of the technical gesture, and to countering the increase of mental pressure. Below is the model of the grid used.

Table 1. Example of the grid model used.

\begin{tabular}{|l|l|l|l|l|l|l|}
\hline Indicator & $\begin{array}{l}\text { 1st } \\
\text { descriptor }\end{array}$ & $\begin{array}{l}\text { 2nd } \\
\text { descriptor }\end{array}$ & $\begin{array}{l}\text { Indicator - } \\
\text { descriptor } \\
\text { connection }\end{array}$ & \multicolumn{2}{l|}{ Connection with the performance data } \\
\hline $\begin{array}{l}\text { Technical } \\
\text { fundamental }\end{array}$ & $\begin{array}{l}\text { Technical } \\
\text { proposal }\end{array}$ & $\begin{array}{l}\text { Tactical } \\
\text { proposal }\end{array}$ & Weight & $\begin{array}{l}\text { Degree of } \\
\text { physical } \\
\text { commitment }\end{array}$ & $\begin{array}{l}\text { Degree of } \\
\text { strength }\end{array}$ & $\begin{array}{l}\text { Degree of } \\
\text { speed }\end{array}$ \\
\hline $\begin{array}{l}\text { Identification } \\
\text { of the } \\
\text { fundamental } \\
\text { strokes that } \\
\text { characterize } \\
\text { the game of } \\
\text { tennis. }\end{array}$ & $\begin{array}{l}\text { Description } \\
\text { of a } \\
\text { technical } \\
\text { proposal } \\
\text { useful to } \\
\text { consolidate } \\
\text { the gesture } \\
\text { and } \\
\text { counteract } \\
\text { mental } \\
\text { pressure. }\end{array}$ & $\begin{array}{l}\text { Tactics to } \\
\text { play a more } \\
\text { orderly and } \\
\text { regular } \\
\text { tennis, and to } \\
\text { be much } \\
\text { more solid in } \\
\text { the game. }\end{array}$ & $\begin{array}{l}\text { Evaluate } \\
\text { how much } \\
\text { these } \\
\text { proposals } \\
\text { actually } \\
\text { affect the } \\
\text { technical } \\
\text { gesture, } \\
\text { establishing } \\
\text { the degree } \\
\text { of } \\
\text { connection. }\end{array}$ & $\begin{array}{l}\text { From the } \\
\text { data } \\
\text { collected, the } \\
\text { type of } \\
\text { physical } \\
\text { commitment } \\
\text { relating to } \\
\text { the game } \\
\text { actions and } \\
\text { in relation to } \\
\text { the type of } \\
\text { surface is } \\
\text { established. }\end{array}$ & $\begin{array}{l}\text { The degree } \\
\text { of muscular } \\
\text { effort } \\
\text { associated } \\
\text { with both } \\
\text { rapid and } \\
\text { precise } \\
\text { movements. }\end{array}$ & $\begin{array}{l}\text { Evaluated } \\
\text { in terms } \\
\text { of timing } \\
\text { and } \\
\text { required } \\
\text { game } \\
\text { pace. }\end{array}$ \\
& & & & & \\
\end{tabular}

Specifically, the technical fundamental identified represented the indicator, while the technical and tactical proposals represented the first and second descriptors respectively. The degree of connection between the indicator and the descriptor was then assessed, assigning a qualitative value between three choices: narrow, medium or low connection. In the second phase of the research, the relationship of each of the previously identified elements with the performance data, was descriptively identified. In practice, the degree of physical commitment, the degree of strength and that of speed were assessed for each of the indicators-descriptors identified. Also, in this case, a qualitative value was assigned among the possible alternatives: maximum, medium and minimum commitment. The data is therefore useful to measure the quantity of significant behaviours to qualitatively elaborate the value of each of them compared to the other current behaviours of the quantitative performance and to establish the connections. The results may be useful for any reflections and focus on the reproducibility of the investigated mechanism to other social activities through an educational and training action. 


\section{RESULTS}

Table 2. Fundamentals analysis with related indicators.

\begin{tabular}{|c|c|c|c|c|c|c|}
\hline Indicator & 1st descriptor & 2nd descriptor & $\begin{array}{l}\text { Indicator - } \\
\text { descriptor }\end{array}$ & $\begin{array}{l}\text { Connection v } \\
\text { performance }\end{array}$ & $\begin{array}{l}\text { ith the } \\
\text { data }\end{array}$ & \\
\hline $\begin{array}{l}\text { Technical } \\
\text { fundamental }\end{array}$ & $\begin{array}{l}\text { Technical } \\
\text { proposal }\end{array}$ & Tactical proposal & Weight & $\begin{array}{l}\text { Degree of } \\
\text { physical } \\
\text { commitment }\end{array}$ & $\begin{array}{l}\text { Degree } \\
\text { of } \\
\text { strength }\end{array}$ & $\begin{array}{l}\text { Degree } \\
\text { of } \\
\text { speed }\end{array}$ \\
\hline $\begin{array}{l}\text { Forehand and } \\
\text { Backhand from } \\
\text { the baseline. }\end{array}$ & $\begin{array}{l}\text { The shots from } \\
\text { the baseline } \\
\text { must have fairly } \\
\text { wide margins } \\
\text { both on the net, } \\
\text { and on the } \\
\text { lines that } \\
\text { delimit the } \\
\text { court. }\end{array}$ & $\begin{array}{l}\text { Insert a rope } \\
\text { placed about } 2 \mathrm{~m} \\
\text { above the net. } \\
\text { Training to send } \\
\text { the ball, with high } \\
\text { trajectories and } \\
\text { loaded of top spin, } \\
\text { towards cones } \\
\text { positioned } 2 \mathrm{~m} \text { from } \\
\text { lateral and bottom } \\
\text { lines. }\end{array}$ & Narrow & High & Medium & High \\
\hline $\begin{array}{l}\text { The kick and } \\
\text { top-spin } \\
\text { service. }\end{array}$ & $\begin{array}{l}\text { Preliminary } \\
\text { exercises to } \\
\text { the service. } \\
\text { Getting used to } \\
\text { the right ball } \\
\text { throw. }\end{array}$ & $\begin{array}{l}\text { Go over a rope } \\
\text { positioned about } \\
2 m \text { above the net } \\
\text { for the kick service; } \\
1 \text { and half meters } \\
\text { for top-spin service. }\end{array}$ & Narrow & High & High & High \\
\hline Volley. & $\begin{array}{l}\text { The racket, } \\
\text { positioned } \\
\text { laterally, } \\
\text { accompanies } \\
\text { the ball forward } \\
\text { from the } \\
\text { bottom } \\
\text { upwards, } \\
\text { imparting a top } \\
\text { spin effect. }\end{array}$ & $\begin{array}{l}\text { The closing hit } \\
\text { must be directed to } \\
\text { the opposite side of } \\
\text { the opponent's } \\
\text { position. }\end{array}$ & Narrow & Medium & Medium & High \\
\hline $\begin{array}{l}\text { Cross-court } \\
\text { shots from the } \\
\text { baseline. }\end{array}$ & $\begin{array}{l}\text { The trajectories } \\
\text { performed with } \\
\text { top-spin and in } \\
\text { open-stance, } \\
\text { will be lower } \\
\text { and more } \\
\text { powerful with } \\
\text { tight crossings. }\end{array}$ & $\begin{array}{l}\text { Usually look for the } \\
\text { diagonals, but } \\
\text { always having good } \\
\text { margins from the } \\
\text { lateral lines. }\end{array}$ & Narrow & High & High & High \\
\hline Drop Shot. & $\begin{array}{l}\text { The ball must } \\
\text { be bounced as } \\
\text { close as } \\
\text { possible above } \\
\text { the net, in the }\end{array}$ & $\begin{array}{l}\text { This is a shot that } \\
\text { calls the opponent } \\
\text { to advance towards } \\
\text { the net. This allows } \\
\text { to take advantage }\end{array}$ & Narrow & Medium & Medium & High \\
\hline
\end{tabular}




\begin{tabular}{|c|c|c|c|c|c|c|}
\hline & $\begin{array}{l}\text { opposite court, } \\
\text { giving a } \\
\text { backward or } \\
\text { lateral effect. }\end{array}$ & $\begin{array}{l}\text { on it and win the } \\
\text { exchange. }\end{array}$ & & & & \\
\hline Smash. & $\begin{array}{l}\text { Positioning and } \\
\text { ball search } \\
\text { exercises are } \\
\text { required. It } \\
\text { must be struck } \\
\text { at the point of } \\
\text { maximum } \\
\text { height, } \\
\text { imparting the } \\
\text { right strength } \\
\text { and precision. }\end{array}$ & $\begin{array}{l}\text { It can be done on } \\
\text { the fly or after a } \\
\text { rebound. } \\
\text { It is basically the } \\
\text { answer to a lob. }\end{array}$ & Narrow & Medium & High & High \\
\hline Lob. & $\begin{array}{l}\text { Hold the } \\
\text { racquet slightly } \\
\text { open, making a } \\
\text { movement that } \\
\text { goes from the } \\
\text { bottom to the } \\
\text { top, giving } \\
\text { maximum } \\
\text { rotation. }\end{array}$ & $\begin{array}{l}\text { Is used to dampen } \\
\text { the opponent's } \\
\text { exchange, slowing } \\
\text { it down. } \\
\text { The execution is } \\
\text { faster when the } \\
\text { opponent is close } \\
\text { to the net. }\end{array}$ & Narrow & Medium & Medium & High \\
\hline
\end{tabular}

\section{DISCUSSION}

The service, the forehand and the backhand from the baseline must be performed taking into account the surface of the court, the presence of an opponent, one's skills and the different game situations (Raiola, 2014). They must be carried out with a practical sense detached from exhibitionism, trying to remember that tennis is a sport that most rewards rationality, commitment and humility. However, this behaviour, which may seem a little cold and rigid, does not exclude the moment of inspiration and imagination. During training, there is also ample space dedicated to pure fun and the pleasure of being with others (Gaetano et al., 2015). To have a more reliable tennis, first of all, the shots from the baseline must have fairly wide margins both on the net and on the lines that delimit the court. The continuous repetitions, with the appropriate corrections and adaptations of the gesture, allow to assimilate and consolidate the fundamental of the game. In the specific case of forehand and backhand from the baseline, the logic suggests slightly high trajectories and top-spin loads. On the other hand, in cross-court shots, the trajectories will be lower and, possibly, along the diagonals. For a better learning of the shots from the baseline, the players should train overcome a rope about two meters above the net, trying send the ball towards cones placed about two meters from the bottom and lateral lines of the court (Bahamonde \& Knudson, 2003). Both the increased height of the net, and the considerable margins from the lateral and bottom lines of the court, are intended to provide more safety and tranquillity in these shots. As for the cross-court shots from the baseline, it is usually necessary to look for the diagonals (where there is greater length and consequent less risk) but always having good margins from the lateral and bottom lines. In this way, the players have the possibility to extend the exchange, if necessary, and make run the opponent. The latter, due to a delay or fatigue, will be forced as soon as possible to make a mistake or a short throw, favouring us with an easy stroke at low risk. This tactic with the crossing shots from the baseline, if well executed, can be used as an attack game as an alternative respect the classic one. It is always 
preferable to have a certain elasticity both in the choice of trajectories, that in the techniques to be adopted (Raiola, 2017). In the topic moments of the match, when the tension rises, the use of precision shots is strongly discouraged to conquer a point that, at first glance, would also seem quite easy to do (Yo0, 2003). To overcome such an annoying moment of tension, it is preferable to send the ball to the other side of the court, with slightly arched trajectories above the net, with decisive and powerful blows (Di Tore et al., 2016). In this way, the players have the opportunity to recover confidence as soon as possible, and a safer and more effective game. In the specific case of the drop shop, it must be performed with a delicate and precise gesture. Otherwise it would be easy prey for the opponent. In similar situations, even a close cross-court shot from the back of the court is not recommended, as the ball should pass over the net and fall early enough, avoiding ending up beyond the lateral line. In both cases the risk of losing the point is very high. The service, like the forehand and backhand, is a technical fundamental performed from the baseline and, in modern tennis, it assumes a predominant importance. Alone he is able to influence the outcome of a match and, at times, also the fate of a whole career. If we want to be consistent with more reliable tennis and, with less mental pressure, we must use this important shot, with the greatest respect and reasoning possible (Raiola, 2015). It should be noted that it is indeed the most important fundamental, but also the most difficult to learn. Furthermore, it is the shot that can most affect our sensitive mind (Raiola, 2019). For a better learning of this fundamental, as before, the player should train by overcome a rope, positioned about two meters above the net (in the kick service) or 1 and a half meters (in the top-spin service) (Bahamonde, 2000). Initially the service in kick is more convenient, giving many rotations to the ball, such as to provide a higher and arched trajectory on the net. When the game situation permits, we can also use the top-spin service as the first ball. It is more powerful and involves greater possibilities of an "ace", perhaps also combined with a good dose of "slice". The lateral rotations of the ball involve a parabolic and elusive trajectory (Robin et al., 2007). With the kick service, the goal is not to immediately make the point, but build the game and forcing the opponent to a weak response from a very distant position (Goulet et al., 1989). All these considerations should lead to a reasoned choice on the type of service to adopted. Even in the flying game it is necessary to look for easy and low risk solutions. First of all, one must be convinced that solving an exchange with a volley is very convenient. If we consider that the volley and, even more, the smash are the easiest fundamentals to acquire, we understand how inserting these game solutions into one's technical-tactical baggage, benefits considerably (Meier et al. 2020). These strokes allow to the player not only to run less, but shorten the time of an exchange, and of the whole match. They also guarantee to shorten recovery times. In general, the closing stroke is performed towards the side opposite to the opponent's position but, when the opponent is able to quickly recover his position, then it may be more convenient to perform a closure on the counterattack. Another tactical solution that allows to move forward for a simple flight closure is the one resulting from an exchange from the baseline, with a high trajectory and lot of top-spin. Even this attack tactic presents a very low risk for the eventual closing shot. It is decided to advance only after evaluating the effectiveness of the approach (D'Isanto et al., 2019). This solution is very rational and profitable. It is necessary to look for the ball in order to impact it well, anticipated and with a rather short arm-racket preparation. When, on the other hand, the player is close to the net, a simple opposition shot (without opening) is preferable, directing the ball towards a short side, away from the opponent. In this situation, professional players often use a "worked" and complex execution, with a good opening and high racket. In this way, a cutting force is imparted to the ball, and a speed difficult to retort (Perry \& Williams, 1998). In conclusion, wanting to briefly summarize the characteristics to hire during an official tennis match, it is always important to have constructive behaviour, avoiding giving negative signals with body language. The players must look for game solutions that give greater security, trying to carefully observe the opponent's behaviour, drawing the right consequences (Patrizia et al., 2019). For the service, it is necessary to prepare with slow, relaxing gestures and with the greatest possible concentration (Groppel \& Roetert, 1992). Finally, they must always assume a very correct behaviour, with maximum availability, and friendliness towards the opponent. Gathering a few points or, even 
winning a match with cunning behaviour, has never improved the career of a tennis player but, certainly, has helped to form a bad judgment on himself by the opponent, the audience present and, over time, of the whole tennis environment.

\section{CONCLUSION}

The technical and tactical behaviours useful to counter the emergence of mental pressure are primarily attributable to the safety of the shot, or to the fact that the shots from the baseline, have fairly wide margins, both above nets, and on the lines that delimit the court. As for the service, it is necessary to consider which technique to adopt. The first is the kick service, with a trajectory with multiple rotations, not very strong but with a good margin to overcome the net. The second is the top-spin service, with a lower trajectory, but much more insidious, taking some more risk. The ideal situation would be to use a top-spin service as the first ball, and possibly the kick service as a second ball. In flight play, finally, the player's only concern must be to run quickly forward, position himself correctly and direct the ball insidiously into the opposite court.

\section{REFERENCES}

Altavilla, G., Furino, F., Marika, D.P., Raiola, G. (2015). Physical skills, sport learning and socio-affective education [Fizičke vještine, sportsko učenje I društveno-afektivno obrazovanje] Sport Science, 8, pp. 44-46.

Altavilla, G. (2019). Monitoring training to adequate the teaching method in training: An interpretative concepts, Journal of Physical Education and Sport, 19, art. no. 258, pp. 1763-1766.

Aryanto, D. B., \& Larasati, A. (2020, January). Factors Influencing Mental Toughness. In 5th ASEAN Conference on Psychology, Counselling, and Humanities (ACPCH 2019) (pp. 307-309). Atlantis Press. https://doi.org/10.2991/assehr.k.200120.066

Bahamonde, R. E. (2000). Changes in angular momentum during the tennis serve. Journal of sports sciences, 18(8), 579-592. https://doi.org/10.1080/02640410050082297

Bahamonde, R. E., and D. Knudson. (2003). Kinetics of the upper extremity in the open and square stance tennis forehand. Journal of Science and Medicine in Sport 6.1, 88-101. https://doi.org/10.1016/s1440-2440(03)80012-9

D'Elia, F., D'Isanto, T., \& Altavilla, G. (2019). Training and performance in the transition period. Journal of Human Sport and Exercise, 14(2proc), S258-S262. https://doi.org/10.14198//hse.2019.14.Proc2.15

Di Tore, P.A., Raiola, G., Altavilla, G., Barba, S., Pignato, S., Lipoma, M. (2016). Motor imagery, perspective taking and gender differences: A VIQ2-based study, Journal of Human Sport and Exercise, 11 (Proc1), pp. S228-S232. https://doi.org/10.14198/jhse.2016.11.proc1.13

D'Isanto, T., D'Elia, F., Raiola, G., Altavilla, G. (2019). Assessment of sport performance: Theoretical aspects and practical indications, Sport Mont, 17 (1), pp. 79-82.

Gaetano, R., Paloma, F.G., Gaetano, A. (2015). Anxiety in the youth physical and sport activity, Mediterranean Journal of Social Sciences, $6 \quad$ (3), pp. 227-230. https://doi.org/10.5901/miss.2015.v6n3s2p227

Gaetano, R., Domenico, T., Gaetano, A. (2015). Physical activity and its relation to body and ludic expression in childhood, Mediterranean Journal of Social Sciences, 6 (3), pp. 293-296. https://doi.org/10.5901/mjss.2015.v6n3s2p293

Galloway, S. M. (2011). The effect of biofeedback on tennis service accuracy. International Journal of Sport and Exercise Psychology, 9(3), 251-266. https://doi.org/10.1080/1612197x.2011.614851 
Goulet, C., Bard, C., and Fleury, M.. (1989). Expertise differences in preparing to return a tennis serve: A visual information processing approach. Journal of sport and Exercise Psychology 11.4: 382-398. https://doi.org/10.1123/jsep.11.4.382

Groppel, J. L., \& Roetert, E. P. (1992). Applied physiology of tennis. Sports Medicine, 14(4), 260-268. https://doi.org/10.2165/00007256-199214040-00004

Lauer, E. E., Lerman, M., Zakrajsek, R. A., \& Lauer, L. (2020). The Creation of a Mental Skills Training Program in Elite Youth Tennis: A Coach-Driven Approach to Developing Resilient, Confident Competitors. International Sport Coaching Journal, 1(aop), 1-8. https://doi.org/10.1123/iscj.20190012

Mamassis, G., \& Doganis, G. (2004). The effects of a mental training program on juniors pre-competitive anxiety, self-confidence, and tennis performance. Journal of Applied Sport Psychology, 16(2), 118137. https://doi.org/10.1080/10413200490437903

Marsico, E., D'Isanto, T., Raiola, G. (2019). The effects of physical exercise on state and trait anxiety. Acta Kinesiologica, 13(2), 64-73.

Meier, C., Frank, C., Gröben, B., \& Schack, T. (2020). Verbal instructions and motor learning: How analogy and explicit instructions influence the development of mental representations and tennis serve performance. Frontiers in Psychology, 11, 2. https://doi.org/10.3389/fpsyg.2020.00002

Patrizia, T., Guido, F., Roberto, C., Rosaria, S., Salvatore, P., Raiola, G. (2019). The role of the educator/adult in supporting children of pre-school age in learning difficult tasks: The case of the playground "primo sport 0246". Journal of Physical Education and Sport, 19, art. no. 301, pp. 20152023.

Perry, J. D., \& Williams, J. M. (1998). Relationship of intensity and direction of competitive trait anxiety to skill level and gender in tennis. The Sport Psychologist, 12(2), 169-179. https://doi.org/10.1123/tsp.12.2.169

Pisano, M., Viscione, I., Cassese, F.P., Altavilla, G. (2019). Long life learning on physical activity, Journal of Human Sport and Exercise, 14 (Proc4), pp. S691-S697. https://doi.org/10.14198//hse.2019.14.proc4.29

Raiola, G. (2014). Motor control and learning skills according to cognitive and ecological dynamic approach in a vision on behaviorism, cognitive, Gestalt and phenomenology theories, Mediterranean Journal of Social Sciences, 5 (15), pp. 504-506. https://doi.org/10.5901/mjss.2014.v5n15p504

Raiola, G. (2015). Sport skills and mental health. Journal of Human Sport and Exercise, 10(1 proc), S369S376. https://doi.org/10.14198/jhse.2015.10.Proc1.27

Raiola, G. (2017). Motor learning and teaching method Journal of Physical Education and Sport, 17, art. no. 236, pp. 2239-2243.

Raiola, G., D'elia, F., Altavilla, G. (2018). Physical activity and sports sciences between European Research Council and academic disciplines in Italy, Journal of Human Sport and Exercise, 13(proc2), pp. S283-S295. https://doi.org/10.14198/ihse.2018.13.proc2.13

Raiola, G. (2019) Complex study for an epistemology of exercise and sport sciences: A)keyconceptsofboth ERC subpanels and CUN keywords; b) physical training and sport methodology sciences academic disciplines in pedagogy recruitment sector and biomedical one: A correlationships study, Journal of Physical Education and Sport, 19, art. no. 255, pp. 1748-1754.

Robin, N., Dominique, L., Toussaint, L., Blandin, Y., Guillot, A., \& Her, M. L. (2007). Effects of motor imagery training on service return accuracy in tennis: The role of imagery ability. International Journal of Sport and Exercise Psychology, 5(2), 175-186. https://doi.org/10.1080/1612197x.2007.9671818

Smith, R. E., Smoll, F. L., \& Cumming, S. P. (2007). Effects of a motivational climate intervention for coaches on young athletes' sport performance anxiety. Journal of sport and exercise psychology, 29(1), 39-59. https://doi.org/10.1123/jsep.29.1.39 
Yoo, J. (2003). Motivational climate and perceived competence in anxiety and tennis performance. Perceptual and Motor Skills, 96(2), 403-413. https://doi.org/10.2466/pms.2003.96.2.403 